\title{
Álvaro García Linera: el Estado y la comunidad a través de sus lugares de enunciación (1988-2012)
}

\author{
Álvaro García Linera: the State and the comunity through its enunciation place
}

(1988-2012)

Tomás Torres López*

Resumen: El presente artículo busca analizar los conceptos de comunidad y Estado en la obra del Vicepresidente boliviano, Álvaro García Linera. La singularidad del texto radica en que se busca rastrear, desde los primeros libros de su militancia guerrillera hasta sus últimas contribuciones como alta autoridad gubernamental, los nudos, tensiones y continuidades en la elaboración de ellos. El trabajo se realizó mediante la diferenciación analítica que denominamos lugares de enunciación, de esta forma se buscó una aproximación que tuviera en consideración el contexto de producción como también las influencias políticas y sociales que marcaron su producción intelectual.

Palabras clave: Álvaro García Linera, Estado, comunidad, lugar de enunciación, intelectuales.

\begin{abstract}
This article seeks to analyze the concepts of community and State in the work of the Bolivian Vice President, Álvaro García Linera. The uniqueness of the text lies in the fact that it seeks to trace, from the first texts of its guerrilla militancy to its latest contributions as high governmental authority, the knots, tensions and continuities in the elaboration of those elements. The work was carried out through the analytical differentiation that was called enunciation place, in this way we looked for an approach that took into consideration the production context as well as the political and social influences that marked his intellectual production.
\end{abstract}

Key words: Álvaro García Linera, State, community, enunciation place, intellectuals

Recibido: 14 agosto 2018 Aceptado: 22 septiembre 2018 


\section{Introducción}

¿Cuáles son algunas de las coordenadas de discusión dentro del campo intelectual de nuestro continente? Y ¿Cómo se desarrollan? Estas preguntas nos permiten situarnos en un momento fértil para las discusiones de la intelectualidad crítica en nuestro continente, ya que parte importante de ellas tienen que ver los conceptos de Estado y comunidad. Las luchas antineoliberales han abierto un campo de discusión que emergió desde el grito zapatista en la selva Lacandona ${ }^{1}$ y que paralelamente a la irrupción de fuertes movimientos sociales permitieron re-aparecer un campo específico de intelectuales de nuestro continente, los que comenzaron a congregarse entorno a la crítica del modelo neoliberal.

En relación a esto, parte importante de los debates se han producido entorno a la cuestión del Estado. Las posiciones autonomistas como las de Zibechi ${ }^{2}$, Holloway ${ }^{3}$ o Svampa ${ }^{4}$, por nombrar a algunos, o las ligadas a la tradición marxista más ortodoxa ${ }^{5}$ han contrapuesto posiciones para contribuir a pensar la emancipación de los sectores postergados de nuestras sociedades. Igual tratamiento se ha dado respecto de qué sujeto será el que se constituirá como motor de cambios. En este sentido, lo comunitario también cobra especial relevancia, ya que todo apuntaría a la necesidad tomar posición por uno de los dos. El Estado con su centralización del poder político o la comunidad para la democratización de la sociedad civil6.

Álvaro García Linera es una figura de dicho proceso. Durante su trayectoria de vida ha sido parte de momentos de gran impacto en la sociedad boliviana. Desde su participación en la guerrilla llamada Ejército Guerrillero Tupak Katari, pasando por las "interpretaciones" y asesoramiento a sindicatos cocaleros y movimientos sociales hasta llegar al sillón vicepresidencial del Palacio Quemado. En estos diferentes momentos de su vida el autor en cuestión ha escrito material intelectual que le ha permitido ser parte de estos debates mucho antes de tener la posición institucional actual. De este modo, el artículo busca analizar los conceptos de comunidad y Estado para desentrañar las relaciones que operan en la conceptualización realizada por este "sociólogo autodidacta".

A diferencia de muchos lectores críticos de García Linera que observan tensiones de proyectos teóricos en su interior ${ }^{7}$, transformismo político ${ }^{8}$, falta de perspectiva de cambio

\footnotetext{
* Chileno, licenciado en sociología, por la Universidad de Viña del Mar y magíster en sociología por la Universidad Alberto Hurtado. correo: tom.torres.lopez@gmail.com.

1 Franck Gaudichaud, Emancipaciones en América Latina, Quito, Instituto de Altos Estudios Sociales, 2013.

2 Raúl Zibechi, Dispersar el poder: Los movimientos sociales como poderes antiestatales, Santiago de Chile, Quimantú, 2011.

3 John Holloway, Cambiar el mundo sin tomar el poder, Santiago de Chile, LOM, 2011.

4 Maristella Svampa, "Movimientos sociales, matrices socio-polítios y nuevos escenarios en América Latina", OneWorld Perspective, 1, 2010, 1-26.

${ }^{5}$ Atilio Borón, Estado, capitalismo y democracia en América Latina, Buenos Aires, CLACSO, 2003.

6 Massimo Modonesi, "Revolución pasiva. Usos y abusos en América Latina del concepto gramsciano", Gramsciana, 2, 2016, 85-114.

7 Alberto Moreiras, "Democracy in Latin America: Álvaro García Linera, an introduction", Culture, Theory and Critique, 56:3, Inglaterra, Primavera, 2015, 266-282.

8 Fabiola Escárzaga, “El gobierno de Evo Morales y los movimientos sociales en Bolivia”, José Domingo Carrillo (Comp.), Izquierdas y sociedad hacia una historia social en América Latina. México D.F., Universidad autónoma de Aguascalientes, 2011, 149-188.
} 
radical ${ }^{9}$ e incluso traición de los valores revolucionarios ${ }^{10}$, nosotros consideramos que hay un hilo conductor de continuidad. Creemos que estos autores incurren en sobredimensionar la propuesta teórica sin tener en cuenta su atípica trayectoria de vida. En este sentido, los lugares de enunciación son un elemento analítico que hemos introducido para equilibrar el análisis de la obra del actual Vicepresidente. Estos contienen dos elementos: uno diacrónico que hace alusión al contexto de producción de un libro determinado y otro sincrónico que pone de relieve la necesidad de estudiar exhaustivamente la producción total de un autor, y desde ahí, comprender las particularidades de esta. En términos epistemológicos los lugares de enunciación se enmarcan en lo que Löwy en el año 1978 llamó la "sociología de los intelectuales revolucionarios"11 la cual tiene como presupuesto la "totalidad dialéctica" como eje comprensivo, es decir, no podríamos presuponer una determinación sobre lo cultural por efecto de la acción de la infraestructura, sino más bien, pensar en las diferentes esferas del mundo social como tendencias influenciables unas por otras.

Sostenemos que en la producción intelectual de García Linera hay énfasis diferenciados a partir de los lugares de enunciación, lo que no nos permite calificar su teoría de la comunidad y el Estado bajo la noción de ruptura. Por el contrario, observamos ciertas continuidades que van delimitando sus principales objetos de interés a lo largo de toda su vida. Ahora bien, esto no implica que los planteamientos teóricos del autor se mantengan sin modificaciones, sino que, al ser un asiduo lector de la coyuntura, pone hincapié en uno u otro partir de la situación política nacional.

Relacionado a lo anterior, el ejemplo más claro es que las ideas de transformación del Estado, mediante la apropiación de este por parte del bloque "plebeyo" se encuentran en sus planteamientos del EGTK identificados en la comunidad, pero que posteriormente mutan para identificar las fuerzas transformadoras en los movimientos sociales. Adicionalmente a esto, consideramos que cualquier intelectual que se plantee analizar la realidad está, inmediatamente, interviniendo en ella, en consecuencia, debe revisitar constantemente sus postulados y así, potencialmente puede contribuir a su transformación de la realidad, este camino creemos es el que adoptó García Linera.

Su labor como intelectual público, luego de su encarcelamiento, da cuenta de cómo observa el rol que deben desempeñar las ciencias sociales con el campo social. El muro que separa metafóricamente el campo intelectual del político ha intentado ser derribado por este autor que en conjunto con sus pares, creo un colectivo (Grupo Comuna), que desafió los cánones neutralistas de la sociología clásica de los intelectuales y llevó a cabo en profundidad esa "traición" que mencionaba Benda12, para que aflorara un vínculo estrecho entre la acción colectiva y la intelligentsia. Sin dudas este hecho, permitió ampliar las audiencias de las ciencias sociales, y de la sociología en particular modificando la manera en que se comprendía la labor intelectual. Si bien no fue el primer esfuerzo en plantearse este tipo de objetivos, el Taller de

9 Peter Baker, "Can the State learn to live Well?" Culture, Theory and Critique, 56:3, Inglaterra, Primavera, 2015, 283296.

10 Danilla Aguiar, “Do "autonomismo" ao "estatismo" trajetória política e intelectual de Álvaro García Linera”, 2011 en:

https://www.academia.edu/25897932/Do_autonomismo_ao_Estatismo_Trajetória_pol\%C3\%ADtica_e_intelectual_ de_Álvaro_Garc\%C3\%ADa_Linera

11 Michel Löwy, Para una sociología de los intelectuales revolucionarios: la evolución política de Lukacs, 1909-1929. México D.F., Siglo XXI, 1978.

12 Julién Benda, La traición de los intelectuales, Santiago de Chile, Ercilla, 1951. 
Historia Oral Andina (THOA) de Silvia Rivera Cusicanqui comenzó un trabajo de reagrupación de intelectuales que estudiaban críticamente la realidad boliviana en 1994 que, sin dudas importantes, no tuvo el carácter cohesionador que sí logró Comuna entre el campo político e intelectual pero se convirtió en un punto de inicio en la dirección de modificar la labor de los intelectuales. Esto debido a que este grupo social tiene una larga tradición de cercanía con el campo político, pero, parafraseando a García Linera , no investigaban, sino que producían sentido común ${ }^{13}$.

A modo de exponer detalladamente los énfasis diferenciados que propician los lugares de enunciación, es dividiremos el artículo a partir de 5 que hemos identificado. De esta manera, buscamos mostrar lo más nítidamente posible, los principales argumentos que encontramos para sostener la tesis de que no existe un sisma epistémico en la trayectoria de ellos. Finalmente, ofrecemos una visión global para destacar los vínculos entre ellos.

\section{Lugar enunciativo guerrillero (1988-1992)}

Este lugar de enunciación hace referencia al período guerrillero de García Linera. El contexto político y social boliviano, a grandes rasgos, estaba caracterizado por una vuelta a la democracia que no permite establecer la hegemonía de ningún sector político a no ser que logren acuerdos con otras fuerzas minoritarias del parlamento ${ }^{14}$, por ende, los consensos que se generaron en el pacto postdictatorial se centraban en la búsqueda de mantener la paz social y estabilidad del sistema político.

Si bien la izquierda boliviana mayoritariamente aceptó y participó del sistema institucional heredado, hubo un sector que no consideraba que la vía institucional, en ese contexto, fuera el camino adecuado para conseguir cambios radicales. Está posición estaba representada por unos estudiantes llegados de México, que luego de finalizar sus estudios de matemática en la UNAM, volvían a Bolivia, ellos eran: Álvaro García Linera, Raquel Gutiérrez y su hermano Raúl García Linera. Además de ellos hubo un grupo con dirigentes históricos de los movimientos indígenas y campesinos bolivianos, entre ellos Felipe Quispe, el "Mallku”, que en su conjunto formarían el Ejército Guerrillero Tupak Katari15.

Este lugar de enunciación tiene como característica ser un momento de recepción y estudio de los textos de Marx. Uno de sus trabajos dentro de la organización insurgente se basa en la difusión de material ideológico para que campesinos y mineros se sumarán a sus filas. De su labor como ideólogo surge el mote de "Qhananchiri" que significa el que ilumina en lengua Aymara. Además de la distribución ideológica-programática, surge la necesidad de polemizar con la izquierda tradicional boliviana en miras de disputar la conducción del movimiento obrero en los centros mineros que, aunque si bien los intentos y el esfuerzo no faltó, nunca lograron disputar la hegemonía al Partido Comunista de Bolivia ni al Partido Obrero Revolucionario. ${ }^{16}$

En términos teóricos, las influencias del Marx que estudia la comuna rural rusa son apreciables de manera nítida en esta etapa. Por ejemplo, en la idea de convivencia entre modos

\footnotetext{
13 Maristella Svampa, Franklin Ramírez y Pablo Stefanoni, Las vías abiertas de la emancipación conversaciones con Álvaro García Linera, Querétaro, Ocean sur, 2009.

14 Fernando Mayorga, Antinomias: el azaroso camino de la reforma política, La Paz, CESU, 2011

15 Jaime Iturri, EGTK: la guerrilla aymara en Bolivia, La Paz, Ediciones Vaca Sagrada, 1992.

16 Maristella Svampa “et al.”, op. cit., 2009.
} 
de producción diferenciados, donde el hegemónico no impondría una línea cronológica para el desarrollo capitalista. De este modo, García Linera buscan abrir caminos de transición al socialismo para no padecer la modernidad del capital. El comunista alemán no fue el único que intervino en esta visión no lineal de la historia. La experiencia en México, que lo llevó a compartir con guerrilleros centroamericanos, fue también decisiva al momento de constituir su idea del rol que desempeñan los indígenas en la denominada "cuestión nacional".

Esta noción, la de una modernidad alternativa, emerge bajo la concepción de universalización de las fuerzas comunitarias. Sin embargo, para concretarse este proceso debe surgir una fuerza capaz no sólo de tomar sino de transformar el Estado.

En este sentido, el Estado es pensado como expresión cristalizada de las correlaciones de fuerza entre explotados y explotadores. Esto porque el análisis de "Qhananchiri" no sería un tema de disputa entre naciones sino, principalmente, de relaciones de producción, pero que a su vez expresarían un aspecto de la situación político-cultural de la dominación. Al existir modos de producción diferentes entre sí, se generarían formas específicas de producción de valor que influiría en las relaciones sociales generales. ${ }^{17}$

El énfasis que otorga García Linera al Estado en esta etapa es el de la negación de la identidad indígena. Este, al ser una mera abstracción de la sociedad representa a una minoría económica y racialmente beneficiada. De este modo, la comunidad es vista como la potencia capaz de subvertir esta situación histórica. Ahora bien, esto no implica una disputa entre naciones, sino más bien, un llamado a los trabajadores, de diferentes orígenes étnicos a extender las relaciones comunitarias, es decir, "Qananchiri" presenta un análisis cuya centralidad es la lucha de clases. El aparato estatal para ser asaltado debe ser transformado y para ser transformado debe ser asaltado.

Vinculado a esto, la comunidad en esta etapa es pensada como el sujeto capaz de transformar la sociedad boliviana. Es en las relaciones comunitarias donde se afincan las fuerzas del trabajo vivo, es decir, la capacidad creadora de los sectores subalternos la cual sería el preludio del socialismo. La forma política ${ }^{18}$, o sea la expresión fetichizada de las relaciones en el campo político, sería la expresión de la realidad del capital, mientras que la comunidad seria la manera mediante la cual se concretan formas antagónicas a la valorización del valor.

En esta etapa rastreamos un elemento central que se repite, de manera solapada e incluso con otras palabras a lo largo de su trayectoria, a saber, la afirmación estatal ${ }^{19}$. En la última parte de este texto volveremos sobre aquello.

Cabe destacar que, en la búsqueda de concretar formas antagonistas de producción, es que surge la importancia del concepto de nación. Este designaría la afirmación de la constitución política de las comunidades, una especie de espacio de universalización de las experiencias de opresión compartidas ${ }^{20}$. Como negación de esta identidad se encuentra el Estado. La comunidad y la nación son el complemento que permite entender aspectos socioculturales que escapan a la producción directa de valor, es decir, una visión más amplia que la ofrecida por el marxismo ortodoxo de la izquierda tradicional boliviana.

\footnotetext{
17 "Qhananchiri” Introducción al cuaderno de Kovalevsky, La Paz, Ofensiva Roja, 1989.

18 Tomás Torres y Jaime Ortega, "El rechazo de lo inerte: Álvaro García Linera y sus primeras lecturas de Marx", Kavilando, 9:2, Colombia, verano 2017, 457-470.

19 "Qhananchiri" Crítica de la nación y la nación crítica naciente, La Paz, Ofensiva Roja,1990,.

20 Ibid.
} 


\section{Lugar enunciativo carcelario (1992-1997)}

Con la denominada "operación paloma", que consistía en que fuerzas militares y policiales vendieran armas a los guerrilleros, es desarticulado el EGTK. Su fugaz presencia logró marcar un hito importante en la historia reciente boliviana, debido a la focalizada represión de la que fueron objeto puesto que de este modo se aparentaba mantener la frágil estabilidad recuperada de la dictadura de Hugo Banzer.

Una vez encarcelado, le fue muy difícil acceder a material que le permitiera continuar con su producción intelectual. No obstante, podemos hallar una profundización de los temas que trabajaba en la guerrilla. Para aquello, decidió centrarse en el estudio de "El Capital" ya que era uno de los libros que, extrañamente, los guardias le permitían ingresar sin mayor control.

En este lugar de enunciación, quizás el único que permite reflexionar a García Linera sin estar atendiendo a la coyuntura política, produce su libro más importante. Algunos aspectos ahí tratados son: que el aparato estatal es la expresión política de la forma valor y que las formas autónomas en las que se constituyen las comunidades se enfrentarían de manera fragmentaria a las sociabilidades universalizadas que produce el Estado ${ }^{21}$, por ende, las luchas por la emancipación tendrían frente a sí un límite objetivo.

Los limites pragmáticos que implicaba el contexto de militar en una guerrilla, como lo fue la beligerancia constante a las instituciones políticas, no le permitían mostrar de forma clara las conclusiones a las que se aproximaba. Consideramos que, por eso, analiza la forma valor y la forma comunidad como sociabilidades diferenciadas y antagónicas. Ambas maneras de concebir el mundo y las relaciones de producción que conllevan, se encuentran enfrentadas debido a la hegemonía de una por sobre otra. La disputa no versa sobre la necesidad de volver en la historia a formas "superadas" o de asumir las relaciones capitalistas como un momento necesario para el avance del proyecto socialista, sino más bien se trata de comprender que la historia se crea a saltos, interrupciones y retrocesos que, mediante la perpetuación de sociabilidades previas, enfrentadas con las del presente, se desarrolla la vida social.

La comunidad en esta etapa es observada, directamente, como expresión del trabajo vivo. Si bien, como guerrillero, la comunidad representaba las relaciones de producción nocapitalistas donde primaba el valor de uso, en la cárcel, esta toma cuerpo como forma de insubordinación a la objetivación del trabajo. A diferencia de lo que se suele pensar, las influencias de Antonio Negri sobre García Linera se presentan de manera tangible en este período. Las ideas como insubordinación, trabajo vivo o proceso inmediato de trabajo dan cuenta de usos teóricos similares entre ambos ${ }^{22}$. No sería bajo la idea de multitud, en la etapa de intérprete, el punto de encuentro.

La relación entre Estado y comunidad en este lugar de enunciación continúa bajo la lógica de la negación. Nuevamente, comunidad y Estado son dos conceptos vinculados entre sí que, si bien se niegan, ambos se necesitan para propiciar el desarrollo post-capitalista. Las características de estos, formas de producción socializadas y reparto del excedente (comunidad) y la capacidad de universalización de la sociabilidad (Estado), serían las maneras mediante las cuales es posible pensar un diálogo emancipatorio que propicie una duradera

21 Álvaro García Linera, Forma valor y forma comunidad aproximaciones teórica-abstractas a los fundamentos civilizatorios que preceden el ayllu universal, Madrid, Traficantes de Sueños, 2015.

22 Antonio Negri, Los libros de la autonomía obrera, Madrid, Akal, 2004. 
formación social contraria a la modernidad capitalista, ya que si no, se busca lo universal: "Queda en pie (...) lo que podemos llamar los principios de orden y relación entre las acciones locales de autonomía frente a la totalidad general y por una nueva totalidad que, como corolario, nos arroja dos aclaraciones o "rectificaciones" parciales [apuntando al Estado]" 23. Es decir, la aspiración a la totalización no solo puede, sino debe ser el ordenamiento estratégico de las autonomías parciales.

En la cárcel se produce una profundización reflexiva sobre lo planteado por Qhananchiri. Por una parte, existe una despersonalización del antagonismo social para pasar a una abstracción que permita observar cómo las formas que adopta el valor se encuentra en disputa. La modernidad se enfrentaría a la comunidad. Esto puede parecer como la lucha entre dos temporalidades y la apuesta de García Linera puede ser leída como un eterno retorno a formas de vida naturales, sin embargo, no se trata de eso. La disputa se trataría de cómo las relaciones de producción son capaces de generar una construcción socio-cultural antagonista. En consecuencia, la confrontación se entiende mediante la idea de que la centralización de los medios de producción implica, per se, el monopolio del poder político de una clase por sobre el resto de la sociedad (forma valor) contra la democratización del poder político por medio de relaciones comunitarias que afirman la importancia de la cualidad por sobre la cantidad (forma comunidad). De este modo, este período reafirma la necesidad de vincular la posibilidad universalizadora del Estado, que en apariencia es capaz de representar lo general24, con la comunidad ya que esta implica materialmente la democratización política, por ende el primero potencia a la segunda.

\section{Lugar enunciativo de intérprete (1997-2005)}

Posterior a su salida de prisión, García Linera se dedica a realizar clases en la carrera de sociología de la Universidad Mayor de San Andrés. En la academia, comienza a polemizar con el campo intelectual boliviano que había sentenciado la "muerte de la clase obrera". A contrapelo de dicha afirmación, el autor realiza dos investigaciones para estudiar las mutaciones de la clase trabajadora, llegando a la conclusión de que está cambió, se desindicalizó, se diezmó en diferentes centros productivos pequeños, pero no desapareció.

Previo y posterior a estas investigaciones, surge la rebelión conocida como "Guerra del agua", la emergencia de movimientos sociales influenció no sólo a García Linera en particular, sino que a los intelectuales en general, ejemplo de ello son los libros colectivos preparados por el Grupo Comuna, organización de intelectuales que fue parte activa de la difusión de las ideas de cuestionamiento al modelo neoliberal y que contribuyó a configurar la contrahegemonía que desembocaría en la llegada del Movimiento al Socialismo al poder. ${ }^{25}$

A esto debemos sumarle su labor de comentarista político y de asesor de movimientos sindicales y cocaleros que le permite adquirir notoriedad pública como una voz legitimada para interpretar los movimientos sociales y las formas de contestación que se estaban manifestando en la convulsionada Bolivia de principios de siglo.

\footnotetext{
23 Álvaro García Linera, op. cit. 2015, p. 56.

24 Tal y como lo hace el dinero en la explicación que entrega Marx en el reconocido capítulo "El fetichismo de la mercancía" en "El Capital".

${ }_{25}$ Rodrigo Santaella, Intelectuais em movimento: o Grupo Comuna na construcao hegemonica antineoliberal na Bolivia, Rio de Janeiro, Alameda, 2014.
} 
Como "intérprete", García Linera comienza a observar lo que denomina fisura colonial del Estado26. Esta apunta a que las estructuras coloniales de dominación heredadas se reproducirían en el presente. De este modo, el interés respecto del Estado sería entender las cristalizaciones institucionales que adopta esta ruptura. Si bien esto pareciera ser contradictorio con el surgimiento de fuertes movimientos sociales que impugnaban al campo político desde demandas con características anti-neoliberales, no lo es del todo, ya que lo realizado por este "sociólogo autodidacta" se trataba de analizar los problemas que no pudieran ser resueltos sino únicamente por medio de una Asamblea Constituyente que pusiera en el centro la cuestión indígena.

Ahora bien, en este período logra caracterizar tres componentes del Estado (ideas movilizadoras, correlación de fuerzas y entramado institucional), los que le permiten determinar la profundidad de una crisis, como también las maneras de manifestación del ciclo de protestas iniciado en el año 2000 con la "Guerra del Agua". Estos conceptos le permitieron pensar las posibilidades de transformación del Estado, puesto que no bastaría con uno de ellos para generar un cambio radical.

La exclusión de las mayorías indígenas es rastreada desde los orígenes de la República, por ende, no es azaroso el estudio de la fisura colonial, sino más bien una forma de expresar como la política ha sido enajenada de la mayoría de la población boliviana. En este contexto surge la idea de plurinacionalidad como salida a la distancia generada, entre indígenas y política, por los años de Estado hacendal. Cabe destacar que este concepto no fue puesto en discusión exclusivamente por García Linera, sino que por la mayoría de los intelectuales pertenecientes al Grupo Comuna.

Sobre la comunidad se observa un giro reflexivo importante. Al igual que en sus etapas precedentes las formas comunitarias son caracterizadas como trabajo vivo, pero ahora la capacidad de insubordinación está relacionada a la capacidad disruptiva que adopte esta como movimiento social. Es decir, los movimientos sociales son expresión del trabajo vivo y serían, por consiguiente, una forma que asume la comunidad en tiempos de neoliberalismo consolidado.

Este ejercicio intelectual se fundamenta en que existen tipos de movimientos sociales donde la forma comunidad es uno de ellos, aquel que aglutinaría las demandas del movimiento indígena. Pero también hay otros tipos en los que se pueden rastrear influencias de la comunidad como tal27, por ejemplo, en la forma multitud puesto que las relaciones que se establecen entre sus miembros son horizontales, las decisiones son asamblearias y las vocerías revocables tal como sucedería en las organizaciones comunales. Estos se explica porque serían experiencias adoptadas desde la constitución política de las comunidades de los pueblos originarios que es explicada por el propio García Linera ${ }^{28}$.

De este modo, el énfasis en el Estado y la comunidad de esta etapa está puesto en cómo es posible institucionalizar la contestación subalterna iniciada en la Guerra del Agua para que pueda perdurar en el tiempo y que no devenga sólo en una explosión de malestar. En este

\footnotetext{
26 Álvaro García Linera, "Narrativa colonial y narrativa comunal”, 1998, Pablo Stefanoni (Comp.), La potencia plebeya, Buenos Aires, CLACSO, 2009, 251-270.

27 Tomás Torres y César Luzio, “Álvaro García Linera y los movimientos sociales, acercamiento a una definición con énfasis en los lugares de enunciación”, Persona \& Sociedad, 31:2, verano 2017, 72-96.

28 Álvaro García Linera, "Sindicato, multitud y comunidad. Movimientos sociales y formas de autonomía política en Bolivia”, 2001, Pablo Stefanoni (Comp.), La potencia plebeya, Buenos Aires, CLACSO, 2009, 347-422.
} 
contexto, aparece nuevamente la afirmación estatal. La constitución del sujeto político se había realizado por medio de las movilizaciones e incluso creó expresiones políticas como el MAS.

\section{Lugar enunciativo vicepresidencial (2006-2012)}

La llegada a la vicepresidencia implicó grandes cambios respecto de su quehacer intelectual. Si bien continuó su producción teórica, esta se vio afectada fuertemente en términos de volumen.

Tras la celebración de la Asamblea Constituyente en el 2006, la situación del país parecía haberse controlado, sin embargo, la derecha, aliada con el embajador de Estados Unidos en Bolivia, intentó un golpe de Estado que no logró prosperar, pero que como consecuencia, logró posicionarse en las discusiones de la Asamblea, aunque también generó algo inesperado que fue la unificación ciertas posiciones mínimas en la izquierda para sacar adelante el proceso constituyente por el año 2009.29

En consideración de lo anterior, surgen dos conceptos claves para comprender el énfasis de este lugar de enunciación respecto al Estado. Utilizando al conocido sociólogo boliviano, René Zavaleta Mercado, logra posicionar en la discusión la característica aparente del Estado, la cual sería la mistificación de la voluntad colectiva o, en otras palabras, la forma enajenada de representación de la totalidad que tendría su expresión en lo político y en lo geográfico. ${ }^{30}$ El segundo concepto introducido por García Linera es el de Estado integral el cual supondría la apropiación colectiva de él a partir de las fuerzas plebeyas, dejando de lado las subrepresentaciones de los sectores populares e indígenas y marcando soberanía a lo largo y ancho del territorio.

Bajo esa lógica podemos observar una continuidad teórica desde su época guerrillera, ya que que si bien el Estado es una mistificación de la generalidad o una "comunidad ilusoria"31, no deja de tener características de universalización. De igual modo, la llegada a la vicepresidencia no implica que por medio de una administración de nuevo tipo se logren realizar cambios en la fisionomía del Estado, en consecuencia, lo que se requiere, es comprender que la disputa que se libra al interior ${ }^{32}$ de este debe venir acompañada de un correlato social.

Por otro lado, la comunidad no es teorizada detenidamente y más bien se comprende como el preludio de un futuro socialista. En el lugar de enunciación guerrillero, planteamos la idea de que García linera comprende al socialismo como extensión de la comunidad33. El socialismo, dada la condición abigarrada de la sociedad, es decir, la superposición de diferentes modos de producción, organizaciones políticas y temporalidades históricas ${ }^{34}$, no podría

29 Álvaro García Linera, Cómo se derrotó el golpismo cívico-prefectural. La Paz, Vicepresidencia del Estado Plurinacional, 2009.

30 Álvaro García Linera, "Del Estado aparente al Estado integral”, Oscar Cabezas (Comp.), Gramsci desde las orillas, Santiago, La Cebra, 2016, 311-331.

31 Álvaro García Linera, "El Estado y la vía democrática al socialismo", Nueva Sociedad, 259:4, Buenos Aires, primavera 2015, 143-161.

${ }^{32}$ Con esto nos referimos a la etapa de intérprete cuando García Linera caracteriza al Estado con tres elementos, uno de ellos es la correlación de fuerzas, el otro las ideas movilizadoras y finalmente, el armazón institucional.

33 Álvaro García Linera, Socialismo comunitario un horizonte de época, La Paz, Vicepresidencia del Estado Plurinacional, 2015.

${ }^{34}$ Luís Tapia, La condición multisocietal: multiculturalidad, pluralismo y modernidad, La Paz, Muela del diablo, 2002. 
soslayar este problema. Para eso la comunidad, que implica relaciones de producción antagónicas al capital, requiere de mezclar en su constitución política, elementos tradicionales de su historia con una perspectiva estratégica que ponga como horizonte la transformación social.

El socialismo como extensión de la comunidad, implica una mixtura entre formas nocapitalistas de producción con formas post-capitalistas de producción. Estas, las segundas, se encuentran, en ciernes, en las primeras, pero no desarrolladas. De cualquier manera, García Linera propone considerar el concepto de socialismo comunitario para proponer la necesidad de diálogo entre tradiciones, cuestión que ya había intentado realizar en su conocido artículo "Indianismo y marxismo: El desencuentro de dos razones revolucionarias"35

El énfasis en este período está marcado por la cooperación entre comunidad y Estado. Si bien ambos implican tensiones constantes entre uno y otro, estas no serían irresolubles sino creativas. ${ }^{36}$ Ahora bien, el que no exista un tratamiento directo hacia la comunidad como en los períodos precedentes que no significa que pierda importancia, sino más bien que la capacidad de generar un consenso entre ambas partes pasa, primero, por transformar el carácter del Estado, volverlo integral.

\section{Una visión global}

Frente a los lugares de enunciación ya desarrollados podemos establecer ciertos elementos que nos permiten situar puntos de continuidades y otros de disyuntiva que deja abierta la obra de Álvaro García Linera. Recalcamos, nuevamente que no sostenemos que no existen contradicciones en los planteamientos del autor, toda obra viva se va construyendo a partir de presupuestos que pueden ir mutando en el tiempo, pero consideramos que a diferencia de algunas lecturas que se han hecho de ella, como las ya apuntadas, incurren en una interpretación antojadiza que no es capaz de considerar la principal característica de este pensador, el ser un lector constante de la coyuntura política boliviana y Latinoamericana.

En este sentido, García Linera, es un intelectual que constantemente está interviniendo en la realidad, ya sea mediante textos y documentos o, luego de su llegada a la vicepresidencia, como autoridad de gobierno.

En términos de su corpus textual observamos sobre el Estado un elemento que sirve de base para la disputa de este. La afirmación estatal, surge como noción en sus escritos tempranos, cuando teorizaba sobre la relación entre la comunidad y el aparato estatal. Esta surgiría como respuesta a las múltiples autonomías sectoriales de las fuerzas comunitarias que en miras de conquistar la universalización del antagonismo al capital, podrían aproximarse a ver en él la posibilidad de hegemonizarlo: "(...) estos antiguos caracteres comunes -lengua y cultura- adquieren una función nueva, afirmándose ya no solo como simples rasgos comunes de un grupo humano, sino como medios de afirmación y lucha de una comunidad humana con percepción de un destino común nacional-Estatal propio." 37 De esta manera, en sus escritos

\footnotetext{
35 Álvaro García Linera, "Indianismo y marxismo: El desencuentro de dos razones revolucionarias", 2005,Pablo Stefanoni (Comp.), La potencia plebeya, Buenos Aires, CLACSO, 2009, 477-500.

36 Álvaro García Linera, Las tensiones creativas de la revolución la quinta fase del proceso de cambios, La Paz, Vicepresidencia del Estado Plurinacional, 2011.

37 “Qhananchiri”, op. cit.,1990, p, 14.
} 
tempranos, se estaría gestando una concepción del relacional del Estado esto porque en que la afirmación sería la disputa del destino común nacional, es decir, un elemento a disputar.

El paso de una concepción leninista del Estado como aparato de dominación de clase que debe ser sustituído por un semi-Estado 38 daban a entender que no se trata de negar el maquinaria estatal en tanto objeto abstracto que refleja la dominación, sino más bien de ver en él una materialización histórica a partir de cómo el neoliberalismo se iba implementando en Bolivia y como este era capaz de generar una forma particular de Estado.

De este modo, la crítica de "Qhananchiri" apunta a una forma-Estado particular, la neoliberal. De aquí se comprende que este sea pensando, posteriormente en sus reflexiones carcelarias, como una extensión de la relación social general capitalista, como puro fetichismo ${ }^{39}$ para caracterizarlo, en el lugar de enunciación vicepresidencial, como una comunidad ilusoria.

Esto último no deja de ser sugerente, ya que la idea de síntesis incompleta del Estado se encuentra previamente planteada en sus textos guerrilleros, ahí, "Qhananchiri" menciona que: "(...) el Estado político no es más que la abstracción de sí misma de la sociedad civil, de sus desgarramientos reales que son superados imaginariamente como Estado (...)". ${ }^{40}$ Sin embargo, la carga comunitaria no desaparece en la medida en que si bien es ilusoria, tiene potencialidades que hacen de ella un elemento en disputa a la monopolización del poder político que implica la construcción de Estado.

Sin embargo, la afirmación estatal no implicaría la necesidad de "tomar" el Estado, para que desde ese lugar se concrete algún tipo de integración de las comunidades, ya que: “(..)estamos destacando, es la imposibilidad teórica y práctica de reducir el problema a vulgares esquemas de "integración", "respeto con autonomía y financiamiento" (una forma más de confinamiento a reservas), o independentismo democrático-burgués (...)"41. La crítica apunta no a cambiar el ropaje, por decirlo en términos coloquiales, sino a transformarlo desde de la disputa, de ahí la idea de que se genere la conceptualización hacia un nuevo tipo de Estado, ya sea denominado semi-Estado o Estado integral. Esto porque el destino nacional-estatal que mencionamos no podría basarse en las construcciones precedentes que se han heredado de la dominación colonial ${ }^{42}$, ya que en él se afincaría una disputa por el capital étnico mediado por la blanquitud como forma de diferenciación de la cultura legítima. ${ }^{43}$

Esto último es observable en las reflexiones que como vicepresidente realiza en relación al rol del Estado plurinacional ${ }^{44}$ ya que no bastaría con reconocerse como sociedad que alberga diferentes nacionalidades sino transformar un tipo de Estado, excluyente y patrimonial por uno "otro", uno que intentara sintetizar en su seno las contradicciones que implica la condición multisocietal de Bolivia.

En relación a la comunidad hay un tránsito relevante en los diferentes lugares de enunciación. Para Qhananchiri las relaciones comunitarias y la comunidad en general, no hacen referencia a un momento histórico determinado, sino más bien a formas particulares de las

38 "Qhananchiri”, Las condiciones de la revolución socialista en Bolivia. A propósito de obreros, Aymaras y Lenin, La Paz, Ofensiva Roja, 1988.

39 Álvaro García Linera, op. cit., 2015.

40 "Qhananchiri", op. cit., 1991, p. 3.

41 Ibíd, p. 2.

42 Álvaro García Linera, Estado multinacional, una propuesta democrática y pluralista para la extinción de la exclusión de las naciones indias. La Paz, Malatesta, 2005.

43 Ibid.

44 Álvaro García Linera, El Estado plurinacional, La Paz, Vicepresidencia del Estado Plurinacional de Bolivia, 2009. 
relaciones sociales de producción capaces de producir subjetividades antagónicas a las lógicas del capital. En otras palabras, el autor observa en la comunidad un potencial latente desde la cual se posicionan formas de vida capaces de hacer frente al avance del modo de producción capitalista.

Relacionado a lo anterior, podemos decir que hay una clave en el concepto de comunidad de "Qhananchiri". Sus reflexiones adoptan una perspectiva no teoleológica de la historia razón por la cual los caminos de desarrollo, en sentido estricto del término, son diferentes, múltiples e incluso yuxtapuestos.

Para García Linera la comunidad es una cuestión práctica de constitución de fuerza capaz de devenir totalizante. De ahí que los conceptos como el modo de producción asiático ${ }^{45}$ o las formaciones nacionales oprimidas ${ }^{46}$ sean tan relevantes. La fuerza de cambio radical no reside en un fin establecido por un partido u organización revolucionaria, sino que se va moldeando a la lucha capaz de producir las condiciones necesarias para aquello.

Luego de observar detenidamente en "Forma valor y forma comunidad" 47 los términos en disputa (modernidad y comunidad), García Linera comienza a observar el surgimiento del bloque plebeyo. De ahí, por ejemplo, que, en los análisis de los movimientos sociales, en el lugar de "intérprete", destaca la parte simbólica-cultural que irradia la sociabilidad comunitaria. Por eso, la forma comunidad como tipo de movilización social influenciaría a la forma multitud en sus formas orgánicas. ${ }^{48}$ Ahora bien, el ejercicio intelectual realizado por el matemático para entrelazar lo comunitario con los movimientos sociales pasa por pensar la comunidad como clase social ${ }^{49}$, es decir, como víctimas de las relaciones capitalistas de producción que comparten cierta cultura y forma productiva común.

Lo anterior no implica que la comunidad haya perdido sus características de latencia emancipatoria, sino que su aplicación práctica, al contexto de movilizaciones sociales, sería mediante la extensión de las lógicas comunitarias que son descritas por García Linera en su período de enunciación carcelaria. De este modo, tal como el propio "sociólogo autodidacta" menciona en una entrevista con Pablo Stefanoni, Maristella Svampa y Franklin Ramírez ${ }^{50}$ sus intereses investigativos serían mezclar el proceso técnico del trabajo, que encuentra en el Proceso de Trabajo Inmediato, y en las construcciones simbólico-culturales de las clases. ${ }^{51}$

De esta manera, se constituye un ejercicio teórico que consideramos permite dar una hebra de continuidad que se inician en el EGTK.. Los movimientos sociales pasan a ocupar gran parte de su reflexión, estos serían el motor de conformación del bloque plebeyo que podría llegar a conformarse como bloque de poder.

Un segundo aspecto importante que se vislumbra hasta ahora es el de que García Linera busca contornear un nuevo sujeto político. En sus investigaciones sobre la condición obrera 52

45 "Qhananchiri” op. cit., 1989.

46 "Qhananchiri", op. cit. 1990.

47 Álvaro García Linera, op. cit., 2015.

48 Álvaro García Linera, op. cit., 2001.

49 Álvaro García Linera, “¿Es el Manifiesto Comunista un arcaísmo político, un recuerdo literario? Cuatro tesis sobre su actualidad histórica”, 1999, Pablo Stefanoni (Comp.), La potencia plebeya, Buenos Aires, CLACSO, 2009, 71-172.

50 Maristella Svampa, "et al”, op. cit., 2009.

51 Ibid, p. 24.

52 Álvaro García Linera, Reproletarización. Nueva clase obrera y desarrollo del capital industrial en Bolivia (19521998), La Paz, Muela del diablo, 1999. 
como sobre las construcciones simbólicas de la misma ${ }^{53}$ se puede observar que la fuerza política de la clase trabajadora estaba en franca decadencia luego de la derrota política sufrida a manos de los militares en la denominada "Marcha por la Vida". ${ }^{54}$ Ahora bien, si observamos sus escritos durante la guerrilla, podemos ver que el discurso de sublevación no va dirigido a los indígenas en abstracto, es decir, a un concepto, en sentido filosófico, sino que apunta a los trabajadores pertenecientes a las naciones oprimidas 55 , ya que la introducción del capitalismo en el campo boliviano habría penetrado en las naciones originarias generado diferencias de clase en su interior.

En el año 2000 observa en las movilizaciones sociales generadas a partir del intento de privatización del agua la emergencia de un sujeto que no tiene una identidad pura, ni sindical ni indígena, sino más bien múltiple.

De este modo, comienza a teorizar sobre el bloque plebeyo. Este concepto, permitió acelerar sus reflexiones precedentes sobre la "afirmación estatal" y sobre la capacidad que tiene el Estado de universalizar y potenciar las fuerzas subalternas en miras de avanzar hacia un horizonte socialista. De la misma manera, las reflexiones sobre la comunidad pasan de una centralidad en las relaciones de producción no-capitalistas de latencia libertaria del trabajo vivo (en las enunciaciones guerrillera y carcelarias) a las formas de subjetivación que generan la sociabildad comunitaria, presente en los movimientos sociales bolivianos del año 2000 en adelante. Este bloque de poder en conformación ${ }^{56}$ tendría características urbanas y rurales, campesinas y obreras, intelectuales y mineras, es decir, la composición de clase es más bien heterogénea, sin embargo, la hegemonía de esta fuerza social emergente que se asomaba en la historia debía recaer en los movimientos de indígenas y en los trabajadores ${ }^{57}$.

Los lugares de enunciación nos permiten observar otro elemento aparte de la trayectoria de los conceptos. Mediante la investigación descubrimos que las producciones discursivas de García Linera se modifican a partir de los contextos enunciativos. Las audiencias, en el sentido de Burawoy ${ }^{58}$, se modifican y por ende el vínculo entre intelectual y estas también. Esto lo notamos, por ejemplo, en los libros producidos en sus tiempos de guerrillero (19881992) donde busca interpelar a un sujeto de manera directa, lo que hace que el discurso se focalice a los trabajadores e indígenas. Mientras que como intérprete (1997-2005), si bien se mantiene un llamado e interpelación, ya no es desde el aspecto político, sino que desde la reflexión analítica de proponer lecturas críticas del presente y posibles salidas emancipatorias a dichos momentos. En la vicepresidencia (2006-2012) el dispositivo del discurso se modifica sustancialmente. En este período y el carcelario (1992-1997) se puede apreciar las modificaciones más importantes en este sentido. En el primero porque hay un llamado a la totalidad de las naciones y ciudadanos que componen el Estado plurinacional, incluso en sus

\footnotetext{
53 La condición obrera. Estructuras materiales y simbólicas del proletariado de la minería mediana (1950-1999), La Paz, Muela del diablo, 2000.

54 Manifestación que terminó con la movilización de miles de obreros que se dirigían a La Paz a manifestar su descontento por la aplicación de las políticas neoliberales.

55 “Qhananchiri”, op. cit., 1990.

56 Álvaro García Linera, Luis Tapia, Oscar Vega, Raúl Prada, El Estado. Campo de lucha, La Paz, Muela del diablo, 2010.

57 García Linera, op. cit., 2001.

58 Michael Burawoy, "For a public sociology”, American Sociological Review, 4:28, Washington, Verano, 2005.
} 
libros donde polemiza con otros sectores intelectuales, 59 mientras que el segundo apunta exclusivamente a lectores interiorizados profundamente con la obra de Marx.

De este modo, a partir de nuestro análisis, creemos que García Linera no solo es un intelectual crítico, sino uno que, a lo largo de su trayectoria, busca teorizar la coyuntura e intervenir en ella. Si observamos los diferentes lugares de enunciación podemos ver que, salvo en el período carcelario, el actual vicepresidente, ha estado presente en los hitos políticos más relevantes, tales como: la creación de una de las últimas guerrillas en América Latina, como asesor/actor/comentarista en las movilizaciones del primer quinquenio del siglo y posteriormente como segundo al mando en el Palacio Quemado.

La lectura sistemática de la coyuntura es el marco sobre el cual García Linera produce sus postulados. Más que interesarse en generar extensos tratados que puedan ser implementados en el tiempo, es un intelectual que busca transformar la realidad.

Los lugares de enunciación nos permiten observar las hebras de continuidad en los objetos de estudio, esto claro, a partir de su expresividad en el contexto político y social boliviano. Este punto es el que quizás evidenciaría los aparentes cambios políticos que afectarían su trayectoria. Este aspecto, consideramos, es el que algunos de sus críticos como Moreiras $^{60}$ no consideran al momento de interpretar la producción intelectual de García Linera.

Considerando lo anterior, los lugares enunciativos nos permiten aclarar ciertos aspectos comunes a lo largo de su trayectoria. Por ejemplo, la idea de que el Estado es un monopolio de la legitimidad, de la riqueza y del poder61, parte de la descripción topológica del Estado $^{62}$, se encuentran presentes en sus ideas en el EGTK. Otro ejemplo es la trama de la correlación de fuerzas en el interior del Estado que permite que tanto en la guerrilla, la cárcel y como intérprete esté en la búsqueda de un sujeto que sea capaz de hacer emerger un nuevo bloque de poder que dispute la conducción hegemónica y política del país.

El Estado a lo largo de su trayectoria no pasa por definiciones que de alguna manera vayan siendo selectivas a partir de la situación política, dejando entre ver un cierto oportunismo, sino que analiza los aspectos que según él son centrales para la maquinaria estatal y así abrir posibilidades reales al triunfo de la contestación subalterna. Es decir, si bien García Linera es un lector de la coyuntura, también establece demarcaciones claras con el adversario. De otra manera, la modificación constante de las condiciones de políticas no hubiera permitido que este la ayudara a los sindicatos y movimientos sociales.

En este sentido, más que un giro práctico, de los movimientos sociales a la institucionalidad, que marcaría su trayectoria de vida, lo que observamos es que sus proposiciones políticas se modifican a partir de cómo observa el contexto político más próximo. De esta manera, el Estado, en particular, pasa de un análisis estructural 63 a otro coyuntural. De ahí que el autor hable de diferentes fisuras (colonial y espacial). Las estructuras coloniales heredadas permiten definir un rasgo fundamental en las formaciones estatales de nuestros

\footnotetext{
${ }^{59}$ Hablamos de "La geopolítica de la amazonía" del año 2012 y de "El “onegismo" enfermedad infantil del derechismo del año 2011.

60 Alberto Moreiras, op. cit., 2015.

61 Ver por ejemplo: “Qhananchiri” op. cit., 1990; “Qhananchiri”, op. cit., 1991; Álvaro García Linera, op. cit., 2015 y Álvaro García Linera "et al”., op. cit., 2010.

62 Álvaro García Linera, op. cit., 2010.

${ }^{63}$ Lo decimos por el análisis de sus componentes y su forma de intervención en el campo social, no como una decisión epistemológica.
} 
países, ya que la exclusión de las mayorías indígenas bolivianas no sería sólo una cuestión reciente, sino que nos remonta a la forma de construcción de la República.

El concepto de fisura territorial nos permite comprender de manera acotada en el tiempo de formación de la República hasta la llegada al poder del MAS en el año 2005, como funcionaba un Estado incompleto que no era capaz de tener presencia en la totalidad del territorio, ni mucho menos tenía la capacidad de distribuir el excedente. A esto García Linera lo denomina Estado aparente ${ }^{64}$.

De alguna manera, lo que hace García Linera es poner en perspectiva las diferentes temporalidades históricas que conviven en la abigarrada sociedad boliviana. Por una parte, las herencias coloniales no permiten la participación política de los pueblos originarios y por otra la espacial demuestra cómo, aún en tiempos de hegemonía capitalista en el país andino, se perpetúan modos de extracción de plusvalor ligados a los tiempos de la colonia, ya que al no existir soberanía en territorios donde existen relaciones de producción no-capitalistas conviven formas de dominación como la hacendal y la del régimen de explotación 65 .

En este sentido, la "afirmación estatal" pasa de ser una propuesta para las naciones oprimidas a una opción plebeya, mediante la cual el análisis de la constitución estatal y de la exclusión no sería únicamente para los pueblos originarios, sino que, con el avance del neoliberalismo, ejemplificado en el intento de privatización del agua, demostraría que la exclusión abarcaría diferentes sectores sociales, desde clases medias hasta trabajadores agrícolas y campesinos ${ }^{66}$.

Volviendo sobre este punto, la conformación del bloque plebeyo, desde una mirada de la definición de Estado de García Linera creemos que parte de la estabilidad del Proceso de Cambios se debe a la conformación de este conglomerado heterogéneo donde conviven diferentes sectores, naciones y clases sociales. Ahora bien, y esto con perspectiva de presente, puede ser también que el desgaste de este sea la génesis de una posible derrota electoral. Cabe destacar un punto conflictivo en el lugar de enunciación vicepresidencial. En su texto "El Estado en transición. Bloque de poder y punto de bifurcación"67 García Linera propone que mediante el quiebre de la resistencia reaccionaria, tras pasar por la emergencia de un nuevo imaginario, el empate catastrófico y la renovación de las élites se comenzaría a gestar un período que denomina, punto de bifurcación. Para el vicepresidente, este momento se caracterizaría por la disputa de dos proyectos que terminaría con la imposición de uno de ellos como vencedor.

Sobre ello consideramos que existe un punto que no es abordado, al menos no de manera directa. La conformación del bloque plebeyo, como conglomerado social, es conflictivo y si bien en el punto de bifurcación se logra anular el proyecto del enemigo, este es capaz de rearticularse e intentar influir en una formación político-social tan heterogénea como esta. Por lo cual, el punto de bifurcación más que marcar un nuevo sentido de época es el origen para confeccionar una nueva hegemonía. Este punto no es abordado por García Linera y parece soslayarlo.

\footnotetext{
64 Álvaro García Linera, op. cit., 2016.

65 Álvaro García Linera, Geopolítica de la amazonía. Poder hacendal-patrimonial y acumulación capitalista, La Paz, Vicepresidencia del Estado Plurinacional de Bolivia, 2012.

${ }^{66}$ Esther Ceceña, La guerra por el agua y por la vida: Cochabamba, una experiencia de construcción comunitaria frente al neoliberalismo y al Banco Mundial, La Paz, Coordinadora por la defensa del agua, 2004.

67 Álvaro García Linera “et al.,”, op. cit., 2010.
} 


\section{Reflexiones finales}

La trayectoria de los conceptos de Estado y comunidad en la obra de Álvaro García Linera pasan por diferentes contextos que van contorneando una reflexión constante sobre aquellos. Una de las características más importantes de esta destacada figura de la intelectualidad crítica latinoamericana es la centralidad que le otorga a la lectura de la coyuntura y por medio de esta a intervenir en el campo político e intelectual. De este modo, los lugares de enunciación, comprendidos como el contexto producción de un libro, en contraste con la trayectoria a largo plazo de su obra, nos permiten aproximarnos a su lectura de una manera que ponga en el centro del debate la capacidad explicativa del presente del autor.

Si bien los conceptos pasan por diferentes contextos estos no son parte de una ruptura que tire por la ventana al bebé con el agua sucia de la bañera, sino justamente nos demuestra que toda construcción teórica está situada históricamente y por ende va sufriendo cambios, pero hay continuidades que se reconocen en sus escritos tempranos de su militancia guerrillera, que cobran mayor densidad en su estadía en la cárcel para que desde ahí los utilice como armazón conceptual para describir y analizar las masivas movilizaciones contra las privatizaciones neoliberales. Cabe destacar, que el recorte temporal obedece a que en el año 2012 publica su último libro por la Vicepresidencia, y si bien posteriormente salieran a la luz recopilaciones de textos, entrevistas y artículos breves, estos no contenían en su interior material nuevo. ${ }^{68}$ En este sentido, la polémica generada a partir de su último texto ${ }^{69}$ no es considerada dentro del análisis, sin embargo, podemos decir dos cosas: primero, a diferencia de lo propuesto por Schavelzon ${ }^{70}$, por ejemplo, consideramos que las reflexiones sobre la revolución en García Linera no han devenido derrotistas, sino más bien se encuentran en la búsqueda por articular la estabilización de un proceso de cambios, para generar condiciones de lucha superiores a las desatadas en el inicio del nuevo milenio en Bolivia, y una nueva distribución de los excedentes generados por el capital. Si a esto lo enmarcamos en lo que el mismo vicepresidente denomina como proceso por oleadas ${ }^{71}$, podríamos considerar que el camino que traza no es el de esperar que se presente una nueva coyuntura social donde explote la potencia plebeya, sino de intentar contestar una pregunta que las izquierdas en general presentan dificultades para responder: ¿Qué hacer con la institucionalidad cuando se es detentada? La solución que ofrece el intelectual boliviano apunta a generar condiciones económicas que permitan, al menos, desarrollar las fuerzas productivas para mantener cubiertas ciertas necesidades básicas de la población indígena y popular. De este modo, cuando se presente, o fomente una oleada, dichos sectores se encontrarían en mejores condiciones para disputar una lucha de más largo aliento. La crítica propuesta por Schavelzon no es nueva y

68 Álvaro García Linera, Estado, democracia, nación, La Paz, Vicepresidencia del Estado Plurinacional, 2013.

${ }^{69}$ Álvaro García Linera, ¿Qué es una revolución? De la revolución Rusa de 1917 a la revolución en nuestros tiempos?, La Paz, Vicepresidencia del Estado Plurinacional de Bolivia, 2017.

70 Salvador Schavenzon, "Teoría de la revolución en Álvaro García Linera: centralización Estatal y elogio de la derrota", s/f. En: http://lobosuelto.com/?p=19497

71 Álvaro García Linera, “¿Fin del ciclo progresista o proceso por oleadas revolucionarias?”, Emir Sader (Comp.), Las vías abiertas de América Latina, Venezuela, CELAG, 2017, 9-48. 
también la han realizado connotados pensadores como Raquel Gutiérrez ${ }^{72}$ y Luis Tapia ${ }^{73}$ y tiene que ver con un debate respecto de hasta donde se es posible avanzar en un contexto de movilización de sectores subalternos, con qué celeridad y qué hacer cuando se experimenta un descenso de la acción colectiva.

El segundo aspecto sobre este debate que nos gustaría destacar es la fuerte influencia leninista en dos lugares de enunciación del intelectual boliviano: la guerrilla y la vicepresidencia. El primero observado en sus reflexiones entorno al Estado y el segundo, parafraseando a Lenin, en sus lecturas de la política como expresión concentrada de la economía. Esta última, más que incurrir en un economicismo, lo que busca es hacer dialogar dos campos que parecieran ir por carriles diferentes, pero que una vez que se conectan, son capaces de hacer cambiar los rumbos de lo social. Esto abre nuevas posibilidades de lectura de la obra de García Linera, sobre todo para acercarse a la producción intelectual más reciente.

Por último, y a pesar de lo anterior, el vicepresidente boliviano más que estar situado en la esfera de los intelectuales institucionales que reniegan de su pasado ${ }^{74}$ continúa tratando de pensar, esta vez desde una posición legitimada en el campo político, las posibilidades de superar una modernidad capitalista que no ha sido capaz de subsumir completamente las formas comunitarias de producción. La potencia plebeya radica justamente ahí, en ver en el Estado una posibilidad de subvertir las condiciones de dominación no mediante una toma metafórica de él sino por medio de la transformación de este.

\section{Bibliografía}

- “Qhananchiri” Crítica de la nación y la nación crítica naciente, La Paz, Ofensiva Roja, 1990.

- "Qhananchiri” Introducción al cuaderno de Kovalevsky, La Paz, Ofensiva Roja, 1989.

- "Qhananchiri", De demonios escondidos y momentos de revolución Marx y la revolución social en las extremidades del cuerpo capitalista parte I, La Paz, Ofensiva Roja, 1991.

- "Qhananchiri”, Las condiciones de la revolución socialista en Bolivia. A propósito de obreros, Aymaras y Lenin, La Paz, Ofensiva Roja, 1988.

- Alberto Moreiras, "Democracy in Latin America: Álvaro García Linera, an introduction", Culture, Theory and Critique, 56:3, Inglaterra, Primavera, 2015, 266-282.

- $\quad$ Álvaro García Linera, ¿Qué es una revolución? De la revolución Rusa de 1917 a la revolución en nuestros tiempos?, La Paz, Vicepresidencia del Estado Plurinacional de Bolivia, 2017.

- $\quad$ Álvaro García Linera, “¿Es el Manifiesto Comunista un arcaísmo político, un recuerdo literario? Cuatro tesis sobre su actualidad”, 1999, Pablo Stefanoni (Comp.), La potencia plebeya, Buenos Aires, CLACSO, 2009, 173-196.

- $\quad$ Álvaro García Linera, “¿Fin del ciclo progresista o proceso por oleadas revolucionarias?”, Emir Sader (Comp.), Las vías abiertas de América Latina, Venezuela, CELAG, 2017, 9-48.

- Álvaro García Linera, "Del Estado aparente al Estado integral”, Oscar Cabezas (Comp.), Gramsci desde las orillas, Santiago, La Cebra, 2016, 311-331.

- $\quad$ Álvaro García Linera, "El Estado y la vía democrática al socialismo", Nueva Sociedad, 259:4, Buenos Aires, primavera 2015, 143-161.

72 Raquel Gutiérrez, Los ritmos del Pachakuti. Movilización y levantamiento popular-indígena en Bolivia (2000-2005), Buenos Aires, Tinta Limón, 2008. Y más recientemente. Raquel Gutiérrez, Horizontes comunitarios-populares. Producción de lo común más allá de las políticas estado-céntricas, España, Traficantes de Sueños, 2017.

${ }^{73}$ Luis Tapia, El Estado de derecho como tiranía, La Paz, CIDES-UMSA-Autodeterminación, 2011.

${ }^{74}$ El ejemplo más icónico de esto podría ser Fernando Henríquez Cardoso, con su célebre "olviden todo lo que escribí." 
- Álvaro García Linera, "Indianismo y marxismo: El desencuentro de dos razones revolucionarias", 2005, Pablo Stefanoni (Comp.), La potencia plebeya, Buenos Aires, CLACSO, 2009, 477-500.

- $\quad$ Álvaro García Linera, "Narrativa colonial y narrativa comunal”, 1998, Pablo Stefanoni (Comp.), La potencia plebeya, Buenos Aires, CLACSO, 2009, 251-270.

- $\quad$ Álvaro García Linera, "Sindicato, multitud y comunidad. Movimientos sociales y formas de autonomía política en Bolivia", 2001, Pablo Stefanoni (Comp.), La potencia plebeya, Buenos Aires, CLACSO, 2009, 347422.

- $\quad$ Álvaro García Linera, Cómo se derrotó el golpismo cívico-prefectural. La Paz, Vicepresidencia del Estado Plurinacional, 2009.

- $\quad$ Álvaro García Linera, El Estado plurinacional, La Paz, Vicepresidencia del Estado Plurinacional de Bolivia, 2009.

- $\quad$ Álvaro García Linera, Estado multinacional, una propuesta democrática y pluralista para la extinción de la exclusión de las naciones indias. La Paz, Malatesta, 2005.

- Álvaro García Linera, Estado, democracia, nación, La Paz, Vicepresidencia del Estado Plurinacional,

2013.

- $\quad$ Álvaro García Linera, Forma valor y forma comunidad aproximaciones teórica-abstractas a los fundamentos civilizatorios que preceden el ayllu universal, Madrid, Traficantes de Sueños, 2015.

- Álvaro García Linera, Geopolítica de la amazonía. Poder hacendal-patrimonial y acumulación capitalista, La Paz, Vicepresidencia del Estado Plurinacional de Bolivia, 2012.

- $\quad$ Álvaro García Linera, La condición obrera. Estructuras materiales y simbólicas del proletariado de la minería mediana (1950-1999), La Paz, Muela del diablo, 2000.

- $\quad$ Álvaro García Linera, Las tensiones creativas de la revolución la quinta fase del proceso de cambios, La Paz, Vicepresidencia del Estado Plurinacional, 2011.

- $\quad$ Álvaro García Linera, Luis Tapia, Oscar Vega, Raúl Prada, El Estado. Campo de lucha, La Paz, Muela del diablo, 2010.

- $\quad$ Álvaro García Linera, Reproletarización. Nueva clase obrera y desarrollo del capital industrial en Bolivia (1952-1998), La Paz, Muela del diablo, 1999.

- $\quad$ Álvaro García Linera, Socialismo comunitario un horizonte de época, La Paz, Vicepresidencia del Estado Plurinacional, 2015.

- $\quad$ Antonio Negri, Los libros de la autonomía obrera, Madrid, Akal, 2004.

- $\quad$ Atilio Borón, Estado, capitalismo y democracia en América Latina, Buenos Aires, CLACSO, 2003.

- $\quad$ Esther Ceceña, La guerra por el agua y por la vida: Cochabamba, una experiencia de construcción comunitaria frente al neoliberalismo y al Banco Mundial, La Paz, Coordinadora por la defensa del agua, 2004.

- $\quad$ Fabiola Escárzaga, "El gobierno de Evo Morales y los movimientos sociales en Bolivia", José Domingo Carrillo (Comp.), Izquierdas y sociedad hacia una historia social en América Latina. México D.F., Universidad autónoma de Aguascalientes, 2011, 149-188.

- $\quad$ Fernando Mayorga, Antinomias: el azaroso camino de la reforma política, La Paz, CESU, 2011

- Franck Gaudichaud, Emancipaciones en América Latina, Quito, Instituto de Altos Estudios Sociales,

2013.

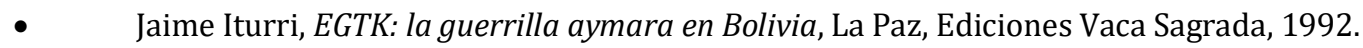

- $\quad J o h n$ Holloway, Cambiar el mundo sin tomar el poder, Santiago de Chile, LOM, 2011.

- Julién Benda, La traición de los intelectuales, Santiago de Chile, Ercilla, 1951.

- $\quad$ Luis Tapia, El Estado de derecho como tiranía, La Paz, CIDES-UMSA-Autodeterminación, 2011.

- $\quad$ Luís Tapia, La condición multisocietal: multiculturalidad, pluralismo y modernidad, La Paz, Muela del diablo, 2002.

- $\quad$ Maristella Svampa, "Movimientos sociales, matrices socio-polítios y nuevos escenarios en América Latina", OneWorld Perspective, 1, 2010, 1-26.

- $\quad$ Maristella Svampa, Franklin Ramírez y Pablo Stefanoni, Las vías abiertas de la emancipación conversaciones con Álvaro García Linera, Querétaro, Ocean sur, 2009.

- Massimo Modonesi, "Revolución pasiva. Usos y abusos en América Latina del concepto gramsciano", Gramsciana, 2, 2016, 85-114. 
- Michael Burawoy, "For a public sociology", American Sociological Review, 4:28, Washington, Verano, 2005.

- Michel Löwy, Para una sociología de los intelectuales revolucionarios: la evolución política de Lukacs, 1909-1929. México D.F., Siglo XXI, 1978.

- $\quad$ Peter Baker, "Can the State learn to live Well?" Culture, Theory and Critique, 56:3, Inglaterra, Primavera, 2015, 283-296.

- $\quad$ Raquel Gutiérrez, Horizontes comunitarios-populares. Producción de lo común más allá de las políticas estado-céntricas, España, Traficantes de Sueños, 2017.

- $\quad$ Raquel Gutiérrez, Los ritmos del Pachakuti. Movilización y levantamiento popular-indígena en Bolivia (2000-2005), Buenos Aires, Tinta Limón, 2008.

- $\quad$ Raúl Zibechi, Dispersar el poder: Los movimientos sociales como poderes antiestatales, Santiago de Chile, Quimantú, 2011.

- Rodrigo Santaella, Intelectuais em movimento: o Grupo Comuna na construção hegemónica antineoliberal na Bolívia, Rio de Janeiro, Alameda, 2014.

- $\quad$ Tomás Torres y César Luzio, "Álvaro García Linera y los movimientos sociales, acercamiento a una definición con énfasis en los lugares de enunciación", Persona \& Sociedad, 31:2, verano 2017, 72-96.

- Tomás Torres y Jaime Ortega, "El rechazo de lo inerte: Álvaro García Linera y sus primeras lecturas de Marx", Kavilando, 9:2, Colombia, verano 2017, 457-470.

\section{Recursos web:}

- Danilla Aguiar, "Do "autonomismo" ao "estatismo" trajetória política e intelectual de Álvaro García Linera", 2011 en:

https://www.academia.edu/25897932/Do_autonomismo_ao_Estatismo_Trajetória_pol\%C3\%ADtica_e_intele ctual_de_Álvaro_Garc\%C3\%ADa_Linera

- $\quad$ Salvador Schavenzon, "Teoría de la revolución en Álvaro García Linera: centralización Estatal y elogio de la derrota", s/f. En: http://lobosuelto.com/?p=19497 